\title{
Photosynthetic model for citrus cultivar Huangguogan
}

\section{Modelo fotossintético para cultivar cítrico Huangguogan}

\author{
Ling Liao ${ }^{1 *}$; Yi Rong ${ }^{1} ;$ Xia Qiü; Tiantian Dong ${ }^{1}$; Zhihui Wang ${ }^{2}$
}

\begin{abstract}
Grafting is an effective measure to improve the photosynthetic rate of citrus. The light responses of photosynthesis in leaves of two-year old grafted Huangguogan (citrus cultivar Huangguogan), Huanggougan / Trifoliate (HG/PT), Huanggougan / Tangerine (HG/CR), and Huanggougan / Ziyang Xiangcheng $(\mathrm{HG} / \mathrm{CJ})$ were studied using the LI-COR 6400 portable photosynthesis system. Lightresponse curves and photosynthetic parameters were analyzed and fitted using the rectangular hyperbola model (RHM), the exponential model (EM), the non rectangular hyperbola model (NRHM), and the modified rectangular hyperbola model (MRHM). The results showed that: (1) Grafting can change the photosynthetic characteristics of Huangguogan, and the value of photosynthesis rate of HG/CJ is the greatest; (2) The light-response curves of net photosynthetic rate (PN), the light compensation point (LCP), and the dark respiration rate (RD) were well fitted using the above four models. The modified rectangular hyperbola was the best model in fitting the data; the nonrectangular hyperbola model was the second, and the rectangular hyperbola model was the poorest one.
\end{abstract}

Key words: Citrus cultivar Huangguogan. Light-response curves. Photosynthetic parameters.

\section{Resumo}

O enxerto é uma medida eficaz para melhorar a taxa fotossintética de citros. As respostas leves da fotossíntese em folhas de Huangguogan (cultivar de citros Huangguogan), Huanggougan / Trifoliate (HG / PT), Huanggougan / Tangerine (HG / CR) e Huanggougan / Ziyang Xiangcheng (HG / CJ) foram estudadas usando o sistema de fotossíntese portátil LI-COR 6400.Curvas de resposta à luz e parâmetros fotossintéticos foram analisados e ajustados usando o modelo de hipérbole retangular (RHM), o modelo exponencial (EM), o modelo de hipérbole não retangular (NRHM) e o modelo de hipérbole retangular modificado (MRHM). Os resultados mostraram que: (1) O enxerto pode mudar as características fotossintéticas de Huangguogan, e o valor da taxa de fotossíntese de HG / CJ é o maior; (2) As curvas de resposta à luz da taxa fotossintética líquida (PN), do ponto de compensação de luz (LCP) e da taxa de respiração escura (RD) foram bem ajustadas usando os quatro modelos acima. A hipérbole retangular modificada foi o melhor modelo na adaptação dos dados; o modelo de hipérbole não-retangular foi o segundo, e o modelo de hipérbole retangular foi o mais pobre.

Palavras-chave: Cultivar cítrico Huangguogan. Curvas de resposta à luz. Parâmetros fotossintéticos.

\footnotetext{
1 Studentes, College of Horticulture, Sichuan Agricultural University, Chengdu, Sichuan, China. E-mail: 1iao19910331@163.com; 597782693@qq.com; 1292156819@qq.com; 741059740@qq.com

2 Prof., College of Horticulture, Sichuan Agricultural University, Chengdu, Sichuan, China. E-mail:wangzhihui_siau@126.com

* Author for correspondence 


\section{Introduction}

Citrus is one of the most economically important fruits worldwide (Xie, Pan, Zhang, Ma, He, Zheng, $\& \mathrm{Ma}, 2017)$. It is grown commercially in over 138 countries and ranks as the top fruit crop in world production. Huangguogan(Citrus reticulata. Citrus sinensis) is a new late maturing, high-yield, and seedless citrus hybrid produced by crossing orange and tangerine. It is mainly cultivated in dryhot valley regions of southwest China (Liao, Cao, Rong, \& Wang, 2016).

Oxygenic photosynthesis is a process by which plants, algae, and cyanobacteria use energy from sunlight to produce sugar and to release oxygen (Blankenship, 2002; Govindjee \& Krogmann, 2004). It is critical for support of life systems on the Earth and it is influenced by many factors, including temperature, carbon dioxide concentration, light intensity, rootstocks, and so on. Photosynthetic efficiency is a critical factor in plant productivity and crop yield (Peng, 2000). Rootstocks play central roles in the light reaction of the photosynthetic process of plants by influencing the leaf structure and leaf pigment content. Grafting superior, commercial cultivars onto rootstocks is a promising tool for improving the efficiency of photosynthesis in production and improving the fruit quality (Georgiou, 2002; FornerGiner, Alcaide, Primo-Millo, \& Fomer, 2003; Bassal, 2009; Castle, Baldwin, \& Muraro, 2010). Morinaga and Ikeda (1990) suggested that the leaf photosynthetic rate and product distribution differ among rootstocks, and scion behavior is probably influenced by rootstock-induced effects on leaf gas exchange (González-Mas, Llosa, \& Quijano, 2009; Rodríguez-Gami, Intrigliolo, Primo-Millo \& Forner-Giner, 2010). Each plant species has its own optimal light intensity range, soil conditions, and other environmental needs for photosynthesis, Studies of the light response of plant photosynthesis under different rootstocks conditions can help to understand the photo-physiological characteristics of different grafted combination, reveal quantitative relationships between these characteristics and grafted combination, and give guidance in plant production processes, such as selection of good quality rootstocks and suitable cultivation conditions.

Light-response models investigate the relationship between $P_{\mathrm{N}}$ and PAR, measuring $P_{\mathrm{N}}$ and fitting these data to a model is important to understand photosynthesis (Robert, Mark, \& John, 1984). It allows to determine the main photosynthetic parameters, such as light saturation point (LSP), light-saturated net photosynthetic rate $\left(P_{\mathrm{N} \max }\right)$, light compensation point (LCP), dark respiration rate (RD), and apparent quantum yield (AQY) can be estimated by drawing light response curves of photosynthesis (Webb, Newton, \& Start, 1974; Ye, 2010; Lang, Wang, Zhang, \& Zhao, 2013). Thus, the commonly used models include the rectangular hyperbola model (RHM) (Baly, 1935), the nonrectangular hyperbola model (NRHM) (Thornley, 1976), the exponential model (EM) (Bassman \& Zwier, 1991), and the modified rectangular hyperbola model (MRHM) (Ye, 2007), all of which have certain advantages and disadvantages (Duan \& Zhang, 2009; Lang et al., 2013). Researchers have applied these models for pamiricus bean (Wang, Yang, Du, Hu, Zhao, \& Mao, 2009), tobacco (Zhong, Zhang, Hu, \& Zhu, 2012), winter wheat (Ye \& Yu, 2008), zizyphus jujube (Xia, Zhang, Wang, \& Zhang, 2014), armeniaca sibirica (Wu, Zhang, Pei, Xu, \& Fang, 2013) and other kinds of plant photosynthesis light response curve fitting, and achieved good results. But these models are not clear if their advantages still hold when applied to citrus plants under different rootstocks conditions. In this research, we used two-year-old potted seedlings of three combinations of grafted plants, Huanggougan/Trifoliate (HG/PT), Huanggougan/ Tangerine (HG/CR), and Huanggougan/Ziyang Xiangcheng $(\mathrm{HG} / \mathrm{CJ})$ to examine the light responses of $P_{\mathrm{N}}$. We analyzed the photosynthetic curves and main parameters and fitted them using the RHM, the EM, the NRHM, and the MRHM. Our objectives 
were to characterize the relationship between photosynthesis and rootstocks, to study the ability of these models to simulate the light response of photosynthesis under different citrus rootstocks conditions, and to gain further understanding of the photo-physiological characteristics of these grafted plants. Our results could also provide guidance for the cultivation of Huangguogan in dry-hot valley regions and for the selection of optimal light response models for cirtus trees under different rootstocks conditions.

\section{Materials and Methods}

Study area: Our experiment was carried out in 2017, the experimental site was located in Pomology and Olericulture Research Institute of Sichuan Agricultural University, Chengdu, Sichuan Province, China. The altitude is $508 \mathrm{~m}$, the average annual precipitation is $966.1 \mathrm{~mm}$, and the average relative humidity is $84 \%$.

Experimental seedling selection: Two-yearold of grafted Huangguogan were selected for experiments. The rootstocks included trifoliate [Poncirus trifoliata (L.) Raf; HG/PT], tangerine (Citrus reticulata Blanco; HG/CR), and Ziyang Xiangcheng [Citrus junos (Sieb.) Tanaka; HG/CJ]. In April 2016, we selected 6 healthy seedlings with relatively uniform plant height and basal diameter for each grafted combination from the local nursery of the Huangguogan Demonstration Garden. Each seedling was planted in a in a pot $(0.5 \mathrm{~m}$ deep with a radius of $0.3 \mathrm{~m}$ ). The trees were raised using standard cultural practices, including fertilization, watering, pest control, and so on. 3 best-growing plants of each grafted combination were selected for the experiments after 360 days.

Measurement of photosynthesis: $P_{\mathrm{N}}$ were measured in 5 fully developed, mature leaves from the center of each plant in response to light. The same leaf was measured 3 times. This was performed using a portable photosynthesis system (LI-COR 6400, LI-COR Inc., Lincoln, NE, USA) between 9:00-11:30h on the same days. During each measurement, $\mathrm{CO}_{2}$ concentration was maintained at $395 \pm 5.0 \mathrm{ppm}$, air temperature at $26-29{ }^{\circ} \mathrm{C}$, and relative humidity at $67 \pm 3.0 \%$. For every observation, PAR was controlled at 2,300; 2,000; 1,800; 1,600; 1,$400 ; 1,200 ; 1,000 ; 800,600,400,200,150,100$, 75,50 , and $0 \mu \mathrm{mol} \cdot \mathrm{m}^{-2} \cdot \mathrm{s}^{-1}$, with an interval of $120 \mathrm{~s}$ by LI-COR LED (LI-COR Inc., Lincoln, NE, USA) irradiation source.

Data processing: We analyzed the photosynthetic parameters data under different rootstocks conditions. By drawing the photosynthetic light response curves $\left(\mathrm{P}_{\mathrm{N}}\right.$-PAR curves) for three grafted combinations using Microsoft Excel 2013, LSP, $P_{\text {Nmax }}$ (J. Chen, Zhang, Zhang \& Wang, 2008; Xia, Zhang, Zhang, \& $\mathrm{Li}, 2009)$, LCP (PAR when $\left.\mathrm{P}_{\mathrm{N}}=0\right)$, and RD $\left(\mathrm{P}_{\mathrm{N}}\right.$ when $\mathrm{PAR}=0$ ) were obtained. At the same time, the AQY was calculated using the linear regression method of the $\mathrm{P}_{\mathrm{N}}-\mathrm{PAR}$ curve under PAR $\leq 200 \mu \mathrm{mol} \cdot \mathrm{m}^{-2} \cdot \mathrm{s}^{-1}$ (Xia et al., 2009; Xu, 2002). These photosynthetic parameters were considered the measured values and they were used to compare with the fitted values obtained using the following models.

Nonlinear fitting of light-response models: Using the SPSS 18.0 for Windows (SPSS, Chicago, USA), light-response curves and photosynthetic parameters were analyzed statistically and fitted nonlinearly using four models: the RHM, the NRHM, the EM, and the MRHM. The initial values used in the models were (1) $\alpha=0.06, \mathrm{RD}=1.0$ for both RHM and EM; (2) $\alpha=0.06, \mathrm{RD}=0.5, \mathrm{k}=0.5$ for the NRHM; (3) $\alpha=0.06, \beta=0.002, \gamma=0.01$, RD $=1.0$ for the MRHM (Ye, 2010; Ye \& Yu, 2008; Ye $\&$ Gao, 2008; Ye \& Wang, 2009). For all models, the initial value of $P_{\text {Nmax }}$ was set to be the integral part of the measured light-saturated net photosynthetic rate.

\section{Rectangular hyperbola model}

The rectangular hyperbola model (Baly, 1935) was expressed as follows:

$$
P_{\mathrm{n}}=\frac{\alpha I P_{\mathrm{n} \max }}{\alpha I+P_{\mathrm{n} \max }}-R_{\mathrm{d}}
$$


where $P_{\mathrm{n}}$ was the net photosynthetic rate, $I$ was the photosynthetic active radiation intensity; $\alpha$ was the initial quantum yield. and $P_{n \max }$ was the maximum net photosynthetic rate.

\section{Nonrectangular hyperbola model}

The Nonrectangular hyperbola model (Thornley, 1976) was expressed as follows:

$$
P_{\mathrm{n}}=\frac{\alpha I+P_{\mathrm{n} \text { max }}-\sqrt{\left(\alpha I+P_{\mathrm{n} \text { max }}\right)^{2}-4 \theta \alpha I P_{\mathrm{n} \text { max }}}}{2 \theta}-R_{\mathrm{d}}
$$

where $P_{\mathrm{n}}$ is the total photosynthetic rate; $\theta(0$ $<\theta \leq 1)$ is the curvilinear angle of the nonrectangular hyperbola; and $\alpha$; I, and $P_{\text {nmax }}$ are as described above.

\section{Exponential model}

The Exponential model (Bassman \& Zwier, 1991) was expressed as follows:

$$
P_{\mathrm{n}}=P_{\text {nmax }}\left(1-e^{-\alpha I / P_{\max }}\right)-R_{\mathrm{d}}
$$

where $\alpha ; I ; P_{\text {nmax }} ; P_{\mathrm{n}}$, and Rd were as described above.

\section{The modified rectangular hyperbola model}

The modified rectangular hyperbola model (Ye, 2007) was expressed by:

$P_{\mathrm{n}}=\alpha_{\mathrm{p}} \frac{1-\beta_{\mathrm{p}} I}{1+\gamma_{\mathrm{p}} I} I-R_{\mathrm{d}}$,

where $\alpha, \beta$, and $\gamma$ were coefficients that were independent of $I(\mathrm{Ye}, 2007)$. All the other parameters were as described above. If $\beta=0, \gamma=\alpha / P_{\text {nmax }}$, the formula (4) equals formula (1).

\section{Results}

Light response of $\boldsymbol{P}_{\mathrm{N}}$ : The light response of $P_{\mathrm{N}}$ to PAR could be divided into three stages (Figure 1), the three stages showed similar patterns of the response regardless of rootstocks for all three grafted combinations, and for different combination, the change scope of the response amplitude is different. In the first stage, where PAR $\leq 200 \mu \mathrm{mol} \cdot \mathrm{m}^{-2} \cdot \mathrm{s}^{-1}, P_{\mathrm{N}}$ increased linearly as PAR increased, indicating that PAR was the key factor influencing photosynthesis in this PAR range; In the second stage, where $400 \mu \mathrm{mol} \cdot \mathrm{m}^{-2} \cdot \mathrm{s}^{-1} \leq \mathrm{PAR} \leq$ $1400 \mu \mathrm{mol} \cdot \mathrm{m}^{-2} \cdot \mathrm{s}^{-1}$, the increase of $P_{\mathrm{N}}$ slowed down because of possible influence by several other factors, such as temperature, $\mathrm{CO}_{2}$ concentration, and leaf characteristics. With the further increase of PAR, the response entered the third stage and the increase of $P_{\mathrm{N}}$ slowed basically maintain invariable or modest decline.

The light response in the second stage was quite diverse under different rootstocks. With increasing PAR, $P_{\mathrm{N}}$ of $\mathrm{HG} / \mathrm{CR}$ has the largest range of rise (Figure 1C), followed by HG/CJ (Figure 1B), and HG/PT (Figure 1A) has the minimum. This shows that although the three stages showed similar patterns of the response, but the response amplitude of the light intensity is $\mathrm{HG} / \mathrm{CR}>\mathrm{HG} / \mathrm{CJ}>\mathrm{HG} / \mathrm{PT}$.

\section{Light-response model of photosynthetic rate:} The light-response curves of Huangguogan leaves under different rootstocks conditions were fitted to 4 models (Figure 1), such as the RHM, the NRHM, the EM, and the MRHM. All 4 models fitted the lightresponse curves of all three grafted combinations well, the 4 fitting curves showed similar patterns of the measured curves of the photo response, although there were some differences. For HG/CR (Figure $1 \mathrm{C})$, the deviation between the 4 fitting curves and the measured ones shows that: the MRHM $<$ the NRHM $<$ the RHM < the EM; For HG/CJ (Figure 1B), the deviation between the 4 fitting curves and the measured ones shows that: the MRHM $<$ the EM $<$ the NRHM < the RHM; For HG/PT (Figure 1A), the deviation between the 4 fitting curves and the measured ones shows that: the MRHM $<$ the $\mathrm{NRHM}<$ the EM $<$ the RHM. Results showed that for three combinations the MRHM shows the best fitting degree with the measured values. 

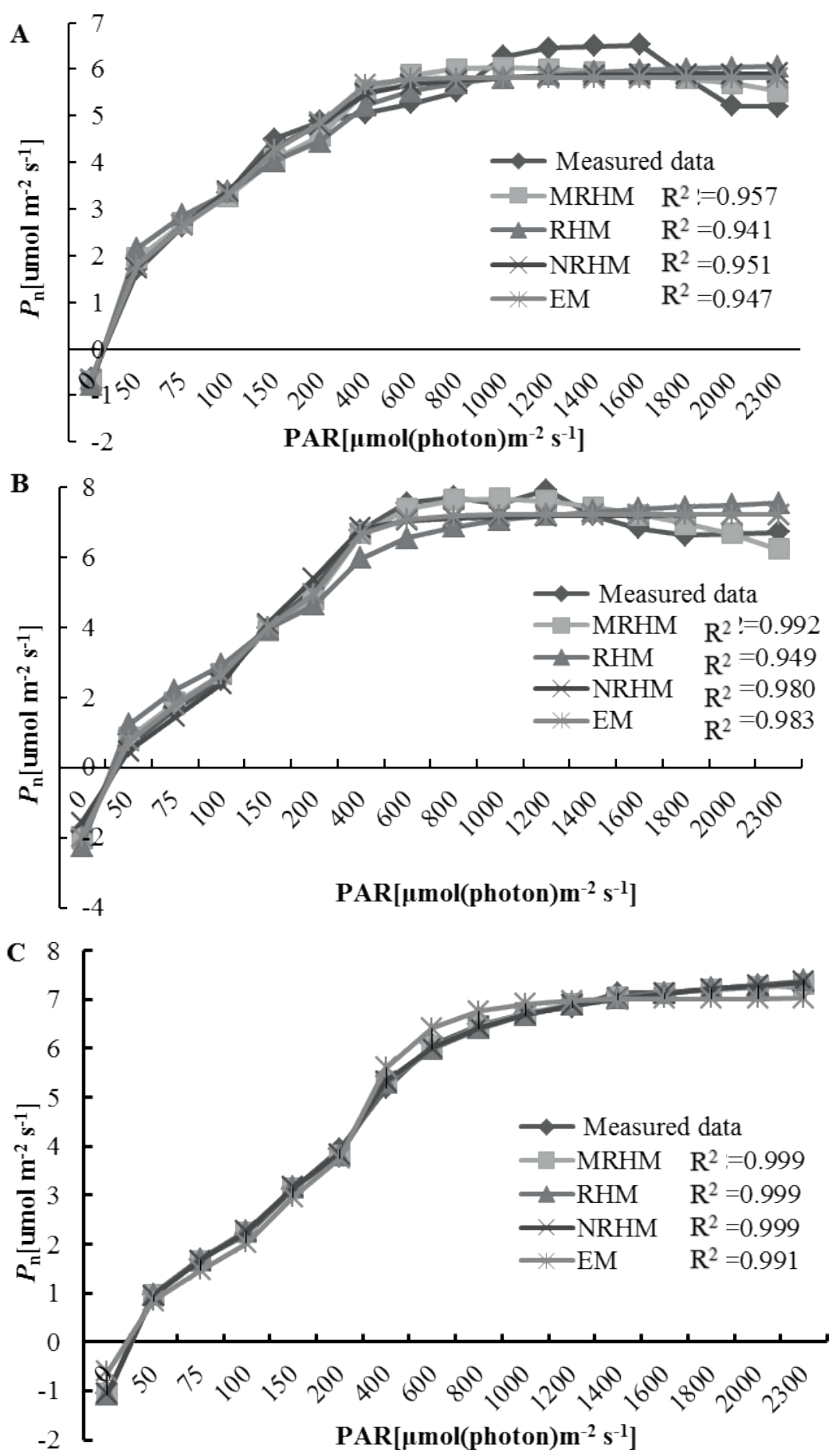

Figure 1. Light response of photosynthetic rate $\left(\mathrm{P}_{\mathrm{N}}\right)$ under different rootstocks conditions in Huangguogan. And simulation of $\mathrm{P}_{\mathrm{N}} / \mathrm{PAR}$ curves of the three tree species by the rectangular hyperbola model; the nonrectangular hyperbola model; the exponential model; and the modified rectangular hyperbola model. $\mathrm{P}_{\mathrm{N}}-$ net photosynthetic rate; PAR - photosynthetically active radiation; $\mathrm{A}-\mathrm{HG} / \mathrm{PT}$; $\mathrm{B}-\mathrm{HG} / \mathrm{CJ} ; \mathrm{C}-\mathrm{HG} / \mathrm{CR}$. 
For three combinations, all 4 models fitted the light-response curves well, as shown by the determination coefficients $\left(R^{2} \geq 94.1 \%\right)$, although there were some differences (Table 1). For HG/CR, the average $R^{2}$ value from all 4 models were greater than $99.9 \%$; For $\mathrm{HG} / \mathrm{CJ}$, the average $R^{2}$ value from the MRHM (99.2\%) was greater than that for the NRHM (98.0\%), these values were followed by those of the EM (97.8\%) and the RHM (94.9\%); For HG/PT, the average $R^{2}$ value from the MRHM $(95.7 \%)$ was also greater than other models.

\section{Table 1}

Fitting four models to the net photosynthetic rate $\left(P_{N}\right)$-light response curves and parameters in cv.Huangguogan. Each value of $P_{N}$ is the mean of 15 replicates. $R^{2}$ - determination coefficient; $R D$ - respiration rate; AQY apparent quantumyield; LCP - light compensation point; $P_{N \max }-$ maximum net photosynthetic rate; LSP light saturation point. RHM - rectangular hyperbola model; NRHM -nonrectangular hyperbola model; EM - exponential model; MRHM - modified rectangular hyperbola model

\begin{tabular}{llllcccc}
\hline Rootstock & Light-response model & AQY & $R^{2}[\%]$ & RD & $P_{\text {Nmax }}$ & LSP & LCP \\
\hline HG/PT & MRHM & 0.078 & 0.957 & 0.697 & 6.032 & 993 & 9.667 \\
& RHM & 0.101 & 0.941 & 0.791 & 7.058 & 310 & 8.818 \\
& NRHM & 0.053 & 0.951 & 0.673 & 6.66 & 257 & 12.817 \\
& EM & 0.055 & 0.947 & 1.114 & 5.815 & 591 & 22.315 \\
HG/CJ & MRHM & 0.074 & 0.992 & 2.018 & 7.680 & 946 & 32.479 \\
& RHM & 0.105 & 0.949 & 2.247 & 10.207 & 387 & 27.379 \\
& NRHM & 0.041 & 0.980 & 1.569 & 8.828 & 298 & 38.540 \\
& EM & 0.050 & 0.978 & 1.276 & 7.210 & 786 & 27.787 \\
HG/CR & MRHM & 0.051 & 0.999 & 1.049 & 7.381 & 3470 & 23.103 \\
& RHM & 0.053 & 0.999 & 1.081 & 9.094 & 431 & 23.077 \\
\hline
\end{tabular}

To evaluate the accuracy of the 4 models, the residual sum of squares (RSS) was calculated according to the formula: $\mathrm{RSS}=\sum(\mathrm{yt}-\hat{\mathrm{y}} \mathrm{t})^{2}$ (Table $2)$, where $\hat{y} t$ is the measured data and $y t$ is the fitted data; neither of these values can be 0 . The greater the RSS, the greater the deviation of the measured value from the fitted value. The smaller the RSS, the better is the fit of the model to the data. The photosynthetic fitting curve of Huangguogan can be divided into three stages. When the PAR was $0-200 \mu \mathrm{mol} \cdot \mathrm{m}^{-2} \bullet \mathrm{s}^{-1}$, the rate of photosynthesis increases rapidly, all models could pass through the measured points well, except the RHM model has some points not fall on the fitted curve of HG/ $\mathrm{CJ}$; while the PAR was $400-1400 \mu \mathrm{mol} \cdot \mathrm{m}^{-2} \bullet \mathrm{s}^{-1}$, part of the measured points of the EM, the NRHM, the MRHM models did not fall on the fitted curve of
HG/PT, part of the measured points of the EM, the NRHM, the RHM models did not fall on the fitted curve of $\mathrm{HG} / \mathrm{CJ}$, but 4 models all can be well through the measured point well of $\mathrm{HG} / \mathrm{CR}$. The rate of photosynthesis were flat or falling when the PAR was $1600-2300 \mu \mathrm{mol} \cdot \mathrm{m}^{-2} \cdot \mathrm{s}^{-1}$, for $\mathrm{HG} / \mathrm{PT}$ and $\mathrm{HG} / \mathrm{CJ}$, only the MRHM model can be well through the measured point well, but 4 models all can be well through the measured point well of $\mathrm{HG} / \mathrm{CR}$.

The AQY is the quantum efficiency calculated according to the number of incident photons, which reflects the power of the plant's light utilization (Table 1). The maximum initial quantum efficiency of the plant is between 0.08- 0.125 in theory and the light response curve tends to be smooth with the increased of light. For good growing crops, the average response is between 0.04-0.07 (Long, 
Humphries, \& Falkowski, 1994; Lu, Yu, Luo, \& Liu, 2001). Yet AQY of some plants is lower than 0.03 even under optimal conditions (Zhang, Wan, Liu, Zhang, \& Wang, 2009; Chen, Zhang, Zhang, \& Wang, 2008; Xia, Zhang, Liu, Han, Chen, \& Liu, 2007). The 4 model fitted the AQY of $\mathrm{HG} / \mathrm{PT}$ is between $0.053-0.101$, the $\mathrm{AQY}$ of $\mathrm{HG} / \mathrm{CJ}$ is between $0.041-0.105$, and the AQY of $\mathrm{HG} / \mathrm{CR}$ is between $0.030-0.053$ (Table 2). The AQY of Huangguogan is between $0-0.125$, that is to say the four models can be used to fit the different rootstock of Huangguogan leaves photosynthetic light response curve, the AQY of HG/CR (0.030-0.053) is at the lower limit range (0.03-0.05) of known plants (Li, 2002). indicating that the HG/CR has low ability to use weak light. For three kinds of the rootstocks, the $\mathrm{HG} / \mathrm{CJ}$, the $\mathrm{HG} / \mathrm{CR}$ has the strongest and weakest ability to use weak light, respectively.

Table 2

Residual sum of squares of light-response curves fitted by four models. RHM - rectangular hyperbola model; NRHM -nonrectangular hyperbola model; EM - exponential model; MRHM - modified rectangular hyperbola model

\begin{tabular}{llccc}
\hline \multirow{2}{*}{ Rootstock } & Light-response model & \multicolumn{3}{c}{ PAR $\left[\mu \mathrm{mol} \mathrm{m}^{-2} \mathrm{~s}^{-1}\right]$} \\
\cline { 3 - 5 } & & $0-200$ & $400-1400$ & $1600-2300$ \\
\hline \multirow{3}{*}{ HG/PT } & MRHM & 0.354 & 1.385 & 0.769 \\
& RHM & 0.689 & 0.987 & 1.769 \\
& NRHM & 0.043 & 1.384 & 1.423 \\
& EM & 0.065 & 1.811 & 1.261 \\
HG/CJ & MRHM & 0.266 & 0.233 & 0.523 \\
& RHM & 1.286 & 3.070 & 2.371 \\
& NRHM & 0.234 & 1.315 & 1.036 \\
& EM & 0.108 & 1.101 & 1.059 \\
HG/CR & MRHM & 0.017 & 0.037 & 0.005 \\
& RHM & 0.019 & 0.040 & 0.018 \\
& NRHM & 0.015 & 0.043 & 0.012 \\
& EM & 0.362 & 0.464 & 0.176 \\
\hline
\end{tabular}

The importance of dark respiration (RD) in plant life is using photosynthetic products to provide energy for metabolism and physiological activities and to provide materials for the synthesis of various biological macromolecules (Xiong, Zeng, Xiao, Zeng, Tu, Jiang, Qiu, Wu, \& Jiang, 2012). The 4 models of $\mathrm{RD}$ fitting rate range for $\mathrm{HG} / \mathrm{PT}, \mathrm{HG} / \mathrm{CJ}$ and $\mathrm{HG} / \mathrm{CR}$ is $0.673-1.114$, 1.276-2.247 and 1.049-1.088, respectively (Table 1). The results show clearly that the $\mathrm{HG} / \mathrm{CJ}$, and the $\mathrm{HG} / \mathrm{PT}$ has the strongest and weakest ability to use consumption of photosynthetic products, respectively. The maximum net photosynthetic rate
$\left(P_{\mathrm{Nmax}}\right)$ is an important parameter of plant growth rate, describing the maximum net light plant potential, and reflecting the maximum potential of plants can be turn the $\mathrm{CO}_{2}$ from the atmosphere into organic matter in the unit area (Xiong et al., 2012). The 4 models fitting $P_{\mathrm{N} \max }$ results shows that the the RHM, the MRHM, the NRHM, and the EM model deviation of the fitted values and the measured values of $\mathrm{HG} / \mathrm{PT}$ is $7.1 \%, 7.5 \%, 9.4 \%, 10.9 \%$, respectively; The 4 models fitting $P_{\text {Nmax }}$ results shows that the MRHM ,the RHM ,the NRHM, and the EM model deviation of the fitted values and the measured values of $\mathrm{HG} / \mathrm{CJ}$ is $3.0 \%, 4.6 \%$, 
$8.8 \%, 8.9 \%$, respectively; and the 4 models fitting $P_{\text {Nmax }}$ results shows that the MRHM , the RHM , the NRHM, and the EM model deviation of the fitted values and the measured values of $\mathrm{HG} / \mathrm{CR}$ is $3.0 \%$, $4.6 \%, 8.8 \%, 8.9 \%$, respectively. Thus, the results shows that the best fitted theoretical model for the $P_{\text {Nmax }}$ is the MRHM model.

The LSP and the LCP reflect the requirement of plants for light conditions. Generally, plants with lower LSP and LCP belong to shade tolerant plants, and conversely, they belong to positive plants. (Xiong et al., 2012). There is no theoretical maximum of the RHM model, NRHM model and EM, fitting the light response data of the linear relationship between $P_{\mathrm{N}}$ and PAR under weak light conditions ( $\mathrm{PAR} \leq 200 \mathrm{umol} \cdot \mathrm{m}^{-2} \cdot \mathrm{s}^{-1}$ ), and combined with the RHM model and NRHM model LSP can be calculated (Liu, Li, \& Xie, 2016). The LSP of the EM is calculated at the maximum of $99 \%$ when the photosynthetic rate is reached (Huang, Dou, Sun, Deng, Wu, G. \& Peng, 2009). 4 models fitted Saturated light intensity $\left(\mathrm{I}_{\mathrm{SAT}}\right)$ values of 3 kinds of rootstocks are as follows: the MRHM model is closest to the measured value, the EM is the second best, the RHM and the NRHM is far less than the measured value. The LCP of heliophyte is 9-18 umol $\cdot \mathrm{m}^{-2} \cdot \mathrm{s}^{-1}$ (Pan, 2001), the LCP of Huangguogan is 8.818-39.834 (Table 1), and from the 4 models, the LCP fitting values of MRHM are most close to the measured values. the LCP of HG/PT is the lowest, which shows that the HG/PT has strong shade resistance.

Plants with lower LCP and higher LSP have stronger adaptability to light environment (Xiong et al., 2012). Comparison the LSP and LCP of 3 kinds of rootstocks shows that $\mathrm{HG} / \mathrm{CR}$ has the strongest adaptability to light environment. The results of Tables 1 and 2 show that the NRHM fitted the RD the best. Therefore, the NRHM also provided the best fit for the AQY and the LCP, and the MRHM provided the best fit for the $P_{\text {Nmax }}$ and the LSP.

\section{Discussion}

Photosynthesis is critical for support of life systems on the Earth. Each plant species has its own optimal light intensity range, soil conditions, and other environmental needs for photosynthesis. Under natural conditions, the photosynthetic rate of citrus is not only lower than $\mathrm{C}_{3}$ crops such as wheat, rice and $\mathrm{C}_{4}$ crops such as corn, but also lower than the pecans, peaches, apples, pears, grapes, blackberry, figs and other fruit (Andersen, 1991; Papadakis, Dimassi, Bosabalidis, Therios, Patakas, \& Giannakoula, 2004), grafting is an effective measure to improve the photosynthetic rate of citrus. Many rootstock types are used for citrus cultivation in China, each having particular advantages and limitations when matched to different geographical regions. Huangguogan has been cultivated for over 300 years in the local, trifoliate [Poncirus trifoliata (L.) Raf], tangerine (Citrus reticulata Blanco), and Ziyang Xiangcheng [Citrus junos (Sieb.) Tanaka] are used frequently in Huangguogan grafting (Liao et al., 2016). A good rootstock should be compatible with the scion cultivar, resistant and/or tolerant to pests and diseases, and adaptable to a wide range of soil types and climatic conditions (Hernández, Pinochet, Moreno, Martínez, \& Legua, 2010). Trifoliate orange is a good germplasm resources, resistance to Citrus tristeza virus (Gmitter, Xiao, Huang, Hu, Garnsey, \& Deng, 1996) and Tylenchulus semipenetrans Cobb (Casde, Tucker \& Krezdom,1993). Another important citrus rootstock in China is tangerine, in Sichuan and Fujian province, tangerine is shown as developed root system, resistance to drought, desert, salt, and root rot. Ziyang Xiangcheng is a good rootstock in alkaline soil, it had strong resistance and tolerance to environmental factors and it is good in fruit quality, adaptability is wide. In this study, the photosynthetic capacity of different kinds of rootstocks is notably different, that is to say grafting can change the photosynthetic characteristics of Huangguogan. The results in this study suggested that with the climate 
conditions in Chengdu, SiChuan province, the value of photosynthesis rate of $\mathrm{HG} / \mathrm{CJ}$ is the greatest, with Ziyang Xiangcheng grafting has heavy development potentiality.

Light response models are essential for studying responses of photosynthesis. Photosynthesis of plant leaves under low light is helpful to determine whether photosynthetic apparatus is functioning normally, and the range of light saturation points in photosynthesis can be measured to understand the photosynthetic capacity of plants under saturated light (Zeng, Yuan, \& Shen, 2002). Many static plant response models (Webb et a1., 1974; Jassby \& Platt, 1976; Marshall \& Biscoe, 1980; Bassman \& Zwier, 1991) and dynamic light response models (Farquhar, Caemmerers \& Berry, 1980; Falkowski \& Wirick, 1981; Fasham \& Platt, 1983; Megard, Tonkyn \& Senti, 1984; Eilers \& Peeters, 1988; Hand, Warren, \& Acock,1993; Zonneveld, 1998; Rubio, Camacho, Sevilla, Chisti, \& Grima, 2003) are now available. The RHM, the NRHM, and the EM are the most widely used. These models are usually evaluated qualitatively (Duan \& Zhang, 2009; Lang et al., 2013), which restricts their accuracy in determining how well the data fit the models. In the practical application, it is found that the maximum net photosynthetic rate is much higher than the measured value when fitting the photo response data with these models (Steel, 1962; Evans, Jakonbsen \& Ogren, 1993; Ye, 2007; Posada, Lechowicz \& Kitajima, 2009), and the light saturation point is much smaller than the measured value (Ye \& Wang 2009; Chen, Peng, Yang, Chen, \& Ou-Yang 2011), and it can't fit the response data of photosynthesis rate decrease with the increase of light intensity after light saturation point (Evans et al., 1993; Yu, Zhang, Liu \& Shi, 2004). There is evidence that the MRHM may overcome disadvantages of the three former models and fit light-response curves and main parameters of photosynthesis more accurately (Ye \& Yu, 2008). The MRHM has been applied mainly to crops and herbaceous plants under different temperatures or different carbon dioxide concentrations (Ye \& Wang, 2009). The AQY is an important indicator of light utilization efficiency by plants. Our study shows that rootstocks is an important factor affecting plant AQY, However, the exact quantitative relationship between rootstocks and AQY is not clear. Recently, a number of models have been quantitatively evaluated by calculating the mean absolute error, the mean square error, or the root mean square error (Chen et al., 2011; Li, Yang, \& Zhang, 2011). However, these evaluation indices have limitations in evaluating the fit of different parameters. In this study, the RRS was used to address this difficulty. The result showed that the MRHM fitted best the $P_{\mathrm{N}}$ light-response curves and parameters and the NRHM provided the next best fit. It was followed by the EM and the RHM. The order of the models from best to worst fit was consistent with the results of studies on Ziziphus jujuba var. spinosus (Xia et al., 2014) and winter wheat (Li et al., 2011). The MRHM fitted the $P_{\text {Nmax }}$ and the LSP well, and the NRHM fitted the RD, the AQY, and the LCP. These data indicated that the MRHM is suitable for light-response parameters at high light intensities and the NRHM is suitable for response parameters at low light intensities (Xia et al., 2014).

Therefore, the MRHM its advantages still hold when applied to citrus plants under different rootstocks conditions.

\section{Conclusion}

Our experiment conducted to study the light response of photosynthesis in Huangguogan under different citrus rootstocks conditions revealed that the thresholds required to reach the light-saturated net photosynthetic rate varied among these three graft combinations. Our results showed that the photosynthetic rate of different rootstocks were different, and the value of photosynthesis rate of $\mathrm{HG} / \mathrm{CJ}$ is the greatest. Although the MRHM did not generate the best fit for $\mathrm{LCP}$ and $\mathrm{RD}$, it did provide the best fit for LSP and $P_{\mathrm{N} \max }$, when compared with the other three models (the RHM, the EM, 
and the NRHM). Moreover, among four models discussed, only the MRHM could successfully fit the light-response curves of photosynthesis and all parameters (LCP, LSP, RD, $\left.P_{\text {Nmax }}\right)$.

\section{References}

Andersen, P. C. (1991). Leaf gas exchange of 11 species of fruit crops with reference to sun-tracking / nonsun-tracking responses. Canadian Journal of Plant Science, 71(4), 1183-1193. doi: 10.4141/cjps91-166

Baly, E. C. (1935). The kinetics of photosynthesis. Proceedings of the Royal Society B: Biology Sciences, 117(804), 218-239. doi: 10.1038/134933a0

Bassal, M. (2009). Growth, yield and fruit quality of 'Marisol' clementine grown on four rootstocks in Egypt. Scientia Horticulturae, 119, 132-137. doi: 10.1016/j.scienta.2008.07.020

Bassman, J., \& Zwier, J. C. (1991). Gas exchange characteristics of Populus trichocarpa, Populus deltoids and Populus trichocarpa $\times$ P. deltoids clone. Tree Physiology, 8(1), 145-159. doi: 10.1093/ treephys/8.2.145

Blankenship, R. E. (2002). Molecular mechanisms of photosynthesis. Oxford: Blackwell Sci.

Castle, W. S., Baldwin, J. C., \& Muraro, R. P. (2010). Performance of 'Valencia' sweet orange trees on 12 rootstocks at two locations and an economic interpretation as a basis for rootstock selection. Hortscience A Publication of the American Society for Horticultural Science, 45(454), 523-533.

Casde, W. S., Tucker, D. H., \& Krezdom, A. H. (1993). Rootstocks for Florida citrus. Gainesville: University of Florida.

Chen, J., Zhang, G. C., Zhang, S. Y., \& Wang, M. J. (2008). Response processes of Aralia elata photosynthesis and transpiration to light and soil moisture. Chinese Journal of Applied Ecology, 19(6), 1185-1190. doi: 10.13287/j.1001-9332.2008.0225

Chen, Z. Y., Peng, Z. S., Yang, J., Chen, W. Y., \& OuYang, Z. M. (2011). A mathematical model for describing light-response curves in Nicotiana tabacum L. Photosynthetica, 49(3), 467-471. doi: 10.1007/s11099-011-0056-5

Duan, A. G., \& Zhang, J. G. (2009). Selection of models of photosynthesis in response to irradiance and definition of attribute of weak light. Forest Research, 22(6), 765-771. doi: 10.1007/978-1-4020-9623-5 5
Eilers, P. H. C., \& Peeters, J. C. H. (1988). A model for the relationship between light intensity and the rate of photosynthesis in phytoplankton. Ecological Modelling, 42(3), 199-215. doi: 10.1016/03043800(88)90057-9

Evans, J. R., Jakonbsen, I., \& Ogren, E. (1993). Photosynthetic light-response curves. Planta, 189(2), 191-200. doi: 10.1007/bf00195075

Falkowski, P. G., \& Wirick, C. D. (1981). A simulation model of the effects of vertical mixing on primary productivity. Marine Biology, 65(1), 69-75. doi: 10.1007/BF00397069

Farquhar, G. D., Caemmerers, S., \& Berry, J. A. (1980). A biochemical model of photosynthetic $\mathrm{CO}_{2}$ assimilation in leaves of $\mathrm{C}_{3}$ species. Planta, 149(1), 78-90. doi: 10.1007/BF00386231

Fasham, M. J. R., \& Platt, T. (1983). Photosynthesis response of phytoplankton to light: a physiological model. Proceedings of the Royal Society B: Biology Sciences, 219(1217), 355-370. doi: 10.1098/ rspb. 1983.0078

Forner-Giner, M. A., Alcaide, A., Primo-Millo, E., \& Fomer, J. B. (2003). Performance of 'Navelina' orange on 14 rootstocks in Northern Valencia. Scientia Horticulturae, 98, 223-232. doi: 10.1016/ S0304-4238(02)00227-3

Georgiou, A. (2002). Evaluation of rootstocks for 'Clementine' mandarin in Cyprus. Scientia Horticulturae, 93(1), 29-38. doi: 10.1016/s03044238(01)00311-9

Gmitter, F. G., Xiao, S. Y., Huang, S., Hu, X. L., Garnsey, S. M., \& Deng, Z. (1996). A localized linkage map of the citrus tristeza virus resistance gene region. Theoretical and Applied Genetic, 92(6), 688-695. doi: 10.1007/BF00226090

González-Mas, M. C., Llosa, M. J., \& Quijano, A. (2009). Rootstock effects on leaf photosynthesis in 'Navelina' trees grown in calcareous soil. Hortscience, 44(2), 280-283. doi: 10.21273/HORTSCI.44.2.280

Govindjee, Krogmann D. (2004). Discoveries in oxygenic photosynthesis (1727-2003): A perspective. Photosynthesis Research, 80(1-3), 15-57. doi: 10.1023/b:pres.0000030443.63979.e6

Hand, D. W., Warren, W. J. W., \& Acock, B. (1993). Effects of light and $\mathrm{CO}_{2}$ on net photosynthetic rates of stands of aubergine and Amaranthus. Annals of Botany, 71(3), 209-216. doi: 10.1006/ anbo.1993.1026 
Hernández, F., Pinochet, J., Moreno, M. A., Martínez, J. J., \& Legua, P. (2010). Performance of Prunus rootstocks for apricot in Mediterranean conditions. Scientia Horticulturae, 124(3), 354-359. doi: 10.1016/j.scienta.2010.01.020

Huang, H. Y., Dou, X. Y., Sun, B. Y. Deng, B., Wu, G., \& Peng, C. (2009). Comparison of photosynthetic characteristics in two ecotypes of Jatropha curcas in summer. Acta Ecologica Sinica, 29(6), 2861-2867. doi: 10.3321/j.issn:1000-0933.2009.06.012

Jassby,A. D., \& Platt, T. (1976). Mathematical formulation of the relationship between photosynthesis and light for phytoplankton. Limnology and Oceanography, 21(4), 540-547. doi: 10.4319/1o.1976.21.4.0540

Liao, L., Cao, S. Y., Rong, Y., \& Wang, Z. H. (2016). Effects of grafting on key photosynthetic enzymes and gene expression in the citrus cultivar Huangguogan. Genetics and Molecular Research, 15(1), 1-10. doi: 10.4238/gmr. 15017690

Lang, Y., Wang, M., Zhang, G. C., \& Zhao, Q. K. (2013). Experimental and simulated light responses of photosynthesis in leaves of three tree species under different soil water conditions. Photosynthetica, 51(3), 370-378. doi: 10.1007/s11099-013-0036-Z

Li H.S. (2002). Modern Plant Physiology. Beijing: Higher Education Press.

Li, Y. X., Yang, Z. Q., \& Zhang, F. C. (2011). Applicability of different photosynthesis models for winter wheat in the Lower Yangtze River. Chinese Journal of Agrometeorology, 32(4), 588-592. doi: 10.3969/j. issn.1000-6362.2011.04.018

Liu, Q., Li, F. R., \& Xie, L. F. (2016). Optimal model of photosynthesis-light response curve in canopy of planted Larix olgensis tree. Chinese Journal of Applied Ecology, 2(8), 2420-2428. doi: 10.13287/ j.1001-9332.201608.023

Long, S. P., Humphries, S., \& Falkowski, P. G. (1994). Photo inhibition of photosynthesis in nature. Annual Review of Plant Physiology and Plant Molecular Biology,45(1), 633- 662. doi: 10.1146/annurev. pp.45.060194.003221

Lu, P. L., Yu, Q., Luo Y., \& Liu, J. D. (2001). Fitting light response curves of photosynthesis of winter wheat. Agricultural Meteorology, 22(2), 12-14. doi: $10.3969 / \mathrm{j}$. issn.1000-6362.2001.02.003

Marshall, B., \& Biscoe, P. V. (1980). A model for $\mathrm{C}_{3}$ leaves describing the dependence of net photosynthesis on irradiance. Journal of Experimental Botany, 31(120), 29-39. doi: 10.1093/jxb/31.1.41
Megard, R. O. D., Tonkyn, W., \& Senti, W. H. (1984). Kinetics of oxygenic photosynthesis in planktonic algae. Journal of Plankton Research, 6(2), 325-337. doi: $10.1093 /$ plankt/6.2.325

Morinaga, K., \& Ikeda, F. (1990). The effects of several rootstocks on photosynthesis, distribution of photosynthetic product, and growth of young satsuma mandarin trees. Journal of the Japanese Society for Horticultural Science, 59(1), 29-34. doi: 10.2503/jjshs.59.29

Pan, R. C. (2001). Plant Physiology. Beijing: Higher Education Press.

Papadakis, I. E., Dimassi, K. N., Bosabalidis, A. M. Therios, I. N., Patakas, A., \& Giannakoula, A. (2004). Effects of B excess on some physiological and anatomical pararneters of 'Navelina' orange plants grafted on two rootstocks. Environmental \& Experimental Botany, 51(2), 247-257. doi: 10.1016/j. envexpbot.2003.11.004

Peng, S. (2000). Single-leaf and canopy photosynthesis of rice. Studies in Plant Science, 7(1), 213-228. doi: 10.1016/S0928-3420(00)80017-8

Hardy, B., Sheehy, J. E., \& Mitchell, P. L. (2000). Redesigning rice photosynthesis to increase yield. Studies in Plant Science, 7(1), 7-10. doi: 10.2135/ cropsci2002.2227

Posada, J. M., Lechowicz, M. J., \& Kitajima, K. (2009). Optimal photosynthetic use of light by tropical tree crowns achieved by adjustment of individual leaf angles and nitrogen content. Annals of Botany, 103(5), 795-805. doi: 10.1093/aob/men265

Rodríguez-Gamir, J., Intrigliolo, D. S., Primo-Millo, E., \& Forner-Giner, M. A. (2010). Relationships between xylem anatomy, root hydraulic conductivity, leaf/ root ratio and transpiration in citrus trees on different rootstocks. Physiologia Plantarum, 139(2), 159-169. doi: 10.1111/j.1399-3054.2010.01351.x

Robert, E. S., Mark, A., \& John, S. B. (1984). Kok effect and the quantum yield of photosynthesis. Plant Physiology, 75(1), 95-101. doi: 10.1104/pp.75.1.95

Rubio, F. C., Camacho, F. G., Sevilla, J. M. F., Chisti, Y., \& Grima, E. M. (2003). A mechanistic model of photosynthesis in microalgae. Biotechnology and Bioengineering, 81(4), 459-473. doi: 10.1002/ bit. 10492

Steel, J. H. (1962). Environmental control of photosynthesis in the sea. Limmol. Oceanogr, 7(2), 137-150. doi: 10.4319/1o.1962.7.2.0137 
Thornley, J. H. M. (1976). Mathematical Models in Plant Physiology. London: Academic Press.

Wang, Z. L., Yang, C. Du, J. C., Hu, H. F., Zhao, L. L., \& Mao, X. T. (2009). Photosynthetic characteristics and photo-adaptability of four Melilotoides ruthenica ecotype. Chinese Journal of Ecology, 28(6), 10351040. doi: 10.13292/j.1000-4890.2009.0187

Webb, W. L., Newton, M., \& Start, D. (1974). Carbon dioxide exchange of Alnus rubra: a mathematical model. Oecologica, 17(4), 281-291. doi: $10.2307 / 4215048$

Wu, Q., Zhang G. C., Pei, B., Xu, Z. Q., \& Fang, L.D. (2013). $\mathrm{CO}_{2}$ response process and its simulation of Prunus sibirica photosynthesis under different soil moisture conditions. Chinese Journal of Applied Ecology, 24(6), 1517-1524. doi: 10.13287/j.10019332.2013.0327

Xia, J. B., Zhang, G. C., Wang, R. R., \& Zhang, S. Y. (2014). Effect of soil water availability on photosynthesis in Ziziphus jujuba var. spinosus in a sand habitat formed from seashells: Comparison of four models. Photosynthetica, 52(2), 253-261. doi: 10.1007/s11099-014-0030-0

Xia, J. B., Zhang, J. Y., Zhang, G. C., \& Li, T. (2009). Photosynthetic and physiological characteristics of three shrubs species in Shell islands of Yellow River Delta. Acta Botanica Boreali-Occidentalia Sinica, 29(7), 1452-1459. doi: 10.3321/j.issn:10004025.2009.07.025

Xia, J. B., Zhang, G.C., Liu, G., Han, W., Chen, J., \& Liu, X. (2007). Light response of Wisteria sinensis leaves physiological parameters under different soil moisture conditions. Chinese Journal of Applied Ecology, 18(1), 30-34. doi: doi:10.1360/yc-007-1324

Xie, R., Pan, X., Zhang, J., Ma, Y., He, S., Zheng, Y., \& Ma, Y. (2017). Effect of salt-stress on gene expression in citrus roots revealed by rna-seq. Functional \& Integrative Genomics, 18(2), 155-173. doi: 10.1007/ s10142-017-0582-8

Xu, D. Q. (2002). Photosynthetic Efficiency. Beijing: Shanghai Science and Technology Publishing House.

Xiong, C. Y., Zeng, W., Xiao, F. M., Zeng, Z.G., Tu, S. Y., Jiang, B., Qiu, F. Y., Wu, Y. F., \& Jiang, X. (2012). An analysis of photosynthetic parameters among Schima superba provenances. Acta Ecologica Sinica, 32(11), 3628-3631. doi: 10.5846/stxb201103080281

Ye, Z. P., \& Wang, J. L. (2009). Comparison and analysis of light-response models of plant photosynthesis. Journal of Jinggangshan University(Natural
Science, 30(2), 9-13. doi: 10.3969/j.issn.16748085.2009.02.002

Ye, Z. P., \& Gao, J. (2008). Change of carboxylation efficiency of Salvia miltiorrhiza in the vicinity of $\mathrm{CO}_{2}$ compensation point. Journal of Northwest University of Agriculture and Forestry Science and Technology Natural Science Edition, 36(5), 160-164. doi: $10.3321 /$ j.issn:1671-9387.2008.05.029

Ye, Z. P., \& Yu, Q. (2008). Comparison of new and several classical models of photosynthesis in response to irradiance. Chinese Journal of Plant Ecology, 32(6), 1356-1361. doi: 10.3773/j.issn.1005264x.2008.06.016

Ye, Z. P. (2010). A review on modeling of responses of photosynthesis to light and $\mathrm{CO}_{2}$. Chinese Journal of Plant Ecology, 34(6), 727-740, doi: 10.3724/ SP.J.1142.2010.40521

Ye, Z. P. (2007). A new model for relationship between irradiance and the rate of photosynthesis in Oryza sativa. Photosynthetica, 45(4), 637-640. doi: 10.1007/s11099-007-0110-5

Ye, Z. P., \& Yu, Q. (2008). A coupled model of stomatal conductance and photosynthesis for winter wheat. Photosynthetica, 46(4), 637-640. doi: 10.1007/ s11099-008-0110-0

Yu, Q., Zhang Y. Q., Liu, Y. F., \& Shi, P. L. (2004). Simulation of the stomatal condutrance of winter wheat in response to light, temperature and $\mathrm{CO}_{2}$ changes. Annals of Botany, 93(4), 435-441. doi: 10.1093/aob/mch023

Zeng, X. M., Yuan, L., \& Shen, Y. G. (2002). Response of photosynthesis to light intensity in intact and detached leaves of Arabidopsis thaliana. Plant Physiology Communications, 38(1), 25-26. doi: 10.13592/j.cnki.ppj.2002.01.007

Zhang, K., Wan, Y. S., Liu, F. Z., Zhang, E. Q., \& Wang, S. (2009). Response of photo-synthetic characteristics of peanut seedlings leaves to low light. Chinese Journal of Applied Ecology, 20(12), 2989-2995. doi: $10.13287 / \mathrm{j} .1001-9332.2009 .0448$

Zhong, C., Zhang, M. D., Hu, X. Q., \& Zhu, Y. (2012). Effects of temperature variation on the light-response characteristics of tobacco leaf photosynthesis. Chinese Journal of Ecology, 31(2), 337-341. doi: 10.13292/j.1000-4890.2012.0066

Zonneveld, C. (1998). Photoinhibition as affected by photo-acclimation in phytoplankton: a model approach. Journal of Theoretical Biology, 193(1), 115-123. doi: 10.1006/jtbi.1998.0688 